\title{
Assessment of the triacylglycerol fraction of olive oil by 1D-NMR spectroscopy: exploring the usefulness of DEPT tool on the peak assignments of ${ }^{13} \mathrm{C}$ NMR spectra
}

\author{
Raquel Garcia ${ }^{1} \cdot$ Arona Pires $^{2} \cdot$ Nuno Martins $^{3} \cdot$ Teresa Carvalho $^{4} \cdot$ Anthony J. Burke $^{2,5} \cdot$ Maria João Cabrita ${ }^{6}$
}

\begin{abstract}
Nuclear magnetic resonance (NMR) spectroscopy has been extensively used to date for the analysis of olive oil samples and constitutes a valuable tool particularly for the study of the triacylglycerol fraction, which is the major fraction of olive oils. In this report, we demonstrate the usefulness of one-dimensional NMR spectroscopy $\left({ }^{1} \mathrm{H}\right.$ and $\left.{ }^{13} \mathrm{C} N M R\right)$ for the nondestructive analysis of the triacylglycerol fraction of olive oils. To achieve this goal, ${ }^{13} \mathrm{C}$ spectral editing technique known as distortionless enhancement by polarization transfer (DEPT), namely ${ }^{13} \mathrm{C}$ NMR DEPT $45,{ }^{13} \mathrm{C}$ NMR DEPT $90,{ }^{13} \mathrm{C}$ NMR DEPT 135 was used for the analysis of the triacylglycerol fraction of the olive oil sample owing to the simplification on peak assignments of ${ }^{13} \mathrm{C}$ spectra. The suitability and usefulness of those DEPT experiments using different angle values in only one pulse sequence will be explored on the interpretation of ${ }^{13} \mathrm{C}$ NMR spectra. In overall, DEPT tool improves the sensitivity of the analysis due to the enhancement in the signal-to-noise ratio, which is important for this type of analysis contributing to the characterization of olive oils.
\end{abstract}

Keywords Olive oil · Fatty acid · Triacylglycerol fraction $\cdot$ Nuclear magnetic resonance (NMR)

Maria João Cabrita

mjbc@uevora.pt

1 ICAAM-Instituto de Ciências Agrárias e Ambientais Mediterrânicas, IIFA, Universidade de Évora, Núcleo da Mitra, Ap. 94, 7006-554 Évora, Portugal

2 Centro de Química de Évora, Universidade de Évora, Rua Romão Ramalho, 59, 7000 Évora, Portugal

3 Aix Marseille Univ, Univ Avignon, CNRS, IRD, IMBE, Marseille, France

4 Instituto Nacional de Investigação Agrária e Veterinária (INIAV I.P.), Elvas, Portugal

5 Departmento de Química, Escola de Ciências e Tecnologia, Universidade de Évora, Rua Romão Ramalho, 59, 7000 Évora, Portugal

6 Departamento de Fitotecnia, Escola de Ciências e Tecnologia, ICAAM-Instituto de Ciências Agrárias e Ambientais Mediterrânicas, Universidade de Évora, Campus da Mitra, Herdade da Mitra, Valverde, 7000-083 Évora, Portugal

\section{Introduction}

Olive oil consists of monounsaturated, polyunsaturated and saturated fatty acids, with glycerol esters (triacylglycerols, TAGs) being the predominant component (Fig. 1), constituting approximately $98 \%$ of the total olive oil composition [1]. Other minor compounds are present in olive oil, including sterols, polyphenols and volatile compounds, that have a fundamental influence on the quality of the olive oil. Olive oil is a very complex and difficult food matrix to analyze [2], because it consists of many different compounds in different concentrations, depending on many factors, such as olive fruit cultivar, olive maturation, geographical location, latitude, climate, as well as the olive fruit processing [3].

The importance of the geographical origin and quality of olive oils has been a concern for the European Union since 1992 , and this has given rise to the denominations-protected designation of origin (PDO) and protected geographical indication (PGI) $[4,5]$ that cover authenticity, quality, cultivar and methods for olive oil production. Therefore, the ascertain of cultivar and geographic origin have aroused a huge interest and some works have explored the suitability of the fatty acids composition and triacylglycerol fraction 
position sn-1

position sn-2

position sn-3

(1)

$$
n=14,16
$$

(2)

$$
\mathrm{CH}_{3}\left(\mathrm{CH}_{2}\right)_{n} \mathrm{COOH}
$$
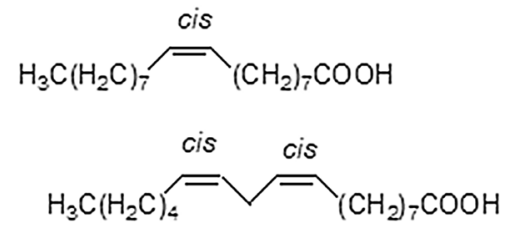

Fig. 1 Basic structure of a triacylglyceride (TAG) proposed by Fisher: (1) shows the structure of the glycerol chain designated by the Greek letters $\alpha, \beta,{ }^{*} \alpha$, and stereospecific numbering $1,2,3$. The structures of the major fatty acids of the oil are also shown: (2) saturated; (3) oleic acid; (4) linoleic acid [1]

combined with multivariate analysis to differentiate olive oil [1]. Gas chromatography (GC) is the most common method for determining the fatty acid composition of oils, including their derivatives [6-8]. It involves the preparation of fatty acid methyl ester (FAMEs) derivatives, rendering these compounds more volatile for analysis by gas chromatography [9]. This procedure is time consuming and the sample is destroyed during the process, which is an important issue to consider when the sample is unique or only available in reduced quantities [2, 6, 10]. Recently, nuclear magnetic resonance (NMR) has proven to be a more straightforward tool to determine the fatty acid composition of olive oils providing detailed information in a single run, without the need of chemical extractions, derivatization or any other modification of the sample $[2,6,10]$. Therefore, many authors have described and investigated the authenticity, quality and geographical origin of olive oils by NMR spectroscopy, since it seems to be a very powerful technique for this purpose [2, $10,11]$. In fact, it allows for a single and quantitative determination of the relative number of molecular groups, which is a good tool for quantifying whole molecular structures, since the intensity of a resonance peak is directly proportional to the number of resonant nuclei. Even in complex matrices, the information for all the components is given in one spectrum, obtained from a sample that does not require derivatization $[6,12]$. Indeed, NMR seems to be a very promising analytical technique for the analysis of olive oils. Some remarkable aspects could be ascribed such as, it not requires the use of reference compounds, does not destroy the samples being possible to recover them, and it analyses simultaneously various components without pre-isolation of the target compounds [13]. Moreover, the process is more sustainable, particularly from an economic point of view.
The 1D NMR spectrum obtained by the single pulse experiment contains a lot of information on the chemical composition of the olive oil providing relevant information about the chemical structure of its metabolites at the molecular level [2]. However, some drawbacks could be ascribed to this technique that are mainly related with their low sensitivity hampering the detection of minor components in complex mixtures such as olive oil. To overcome some of those limitations, several NMR-based approaches have been explored mainly focused on the development of several pulse sequences properly designed to detect some specific compounds, whose identification is crucial for $\mathrm{OO}$ characterization [14].

Table 1 summarizes various applications of 1D NMR spectroscopy used for olive oil analysis. In fact, ${ }^{1} \mathrm{H}$ NMR is the most widely used method, due to the higher sensitivity and lower relaxation times of the proton nuclei relative to the less sensitive ${ }^{13} \mathrm{C}$ NMR nuclei. As observed in Table 1, ${ }^{1} \mathrm{H}$ NMR enables to assess the geographical origin of olive oils as well as the type of cultivar. Moreover, compounds that play a crucial role on the stability of olive oils can also assessed which is particularly relevant for some OO's topics, such as storage and shell-life of olive oils [5, 18, 22-26]. However, ${ }^{1} \mathrm{H}$ NMR is not useful to assign the positional distribution of the fatty acids in the glycerol backbone [2] while ${ }^{13} \mathrm{C}$ NMR spectroscopy provides information at this level since the main resonances observed in the ${ }^{13} \mathrm{C} \mathrm{NMR}$ spectrum belong to triacylglycerides (Fig. 1).

The high resolution ${ }^{13} \mathrm{C}$ NMR technique is considered one of the most powerful methods for analysis of vegetable oils. Through this technique, it is possible to distinguish different cultivars and the geographic origins of different olive oils [28, 29] generally using multivariate statistical analysis [30]. Comparing ${ }^{1} \mathrm{H}$ NMR and ${ }^{13} \mathrm{C}$ NMR spectroscopy, it is well known that the longitudinal relaxation of the ${ }^{13} \mathrm{C}$ NMR experiment is four times lower than that of ${ }^{1} \mathrm{H}$ NMR, being ${ }^{13} \mathrm{C}$ NMR longitudinal relaxation times ranging from 0.5 to $8 \mathrm{~s}$ [17]. To overcome this limitation, a new methodology known as ${ }^{13} \mathrm{C}$ NMR distortionless enhancement by polarization transfer (DEPT) has been explored in the last years. It involves the use of a pulse sequence that transfers polarization from the carbon-13 nuclei to the population of proton nuclei to which they are coupled, making the repeat rate faster because it depends on the shorter relaxation times of the proton nuclei compared to carbon-13 nuclei [17]. This technique proves to be very promising due to an enhancement of the sensitivity of the carbon-13 nuclei that is promoted by the application of a DEPT NMR pulse sequence experiment. Concretely, ${ }^{13} \mathrm{C}$ NMR DEPT plays a crucial role on the assignment of primary, secondary and tertiary carbon atoms, differentiating between $-\mathrm{CH},-\mathrm{CH}_{2}$ and $-\mathrm{CH}_{3}$ groups by variation of the selection angle parameter: $135^{\circ}$ angle gives all $-\mathrm{CH}$ 
Table 1 Application of 1D NMR spectroscopy for olive oil characterization

\begin{tabular}{|c|c|c|c|}
\hline Analytes and type of sample & Nucleus, NMR frequency & Application & References \\
\hline $\begin{array}{l}\text { Triacylglycerol, fatty acids composition in olive } \\
\text { oils }\end{array}$ & ${ }^{13} \mathrm{C}$ DEPT $45,125 \mathrm{MHz}$ & Geographic origin & {$[1]$} \\
\hline $\begin{array}{l}\text { Triacylglycerols, fatty acids composition in olive } \\
\text { oils }\end{array}$ & ${ }^{13} \mathrm{C}$ DEPT45, $125 \mathrm{MHz}$ & Geographic origin and cultivar & [15] \\
\hline $\begin{array}{l}\text { Triacylglycerols, fatty acid composition in olive } \\
\text { oils }\end{array}$ & ${ }^{13} \mathrm{C}$ DEPT45, $125 \mathrm{MHz}$ & Chemical composition & [16] \\
\hline $\begin{array}{l}\text { Triacylglycerol in extra virgin olive oils, olive } \\
\text { oils, olive pomace oils and lampante in olive } \\
\text { oils }\end{array}$ & ${ }^{13} \mathrm{C}$ DEPT $45,125 \mathrm{MHz}$ & Olive oil variety discrimination & {$[17]$} \\
\hline Volatiles, sterols, terpenes, squalene in olive oil & ${ }^{1} \mathrm{H} / 600 \mathrm{MHz},{ }^{13} \mathrm{C} / 62.9 \mathrm{MHz}$ & Geographic characterization & {$[18]$} \\
\hline Fatty acids in olive oil & ${ }^{13} \mathrm{C}, 150.9 \mathrm{MHz}$ & $\begin{array}{l}\text { Chemical composition, cultivar and geographic } \\
\text { origin }\end{array}$ & [19] \\
\hline Squalene in olive oil & ${ }^{13} \mathrm{C}, 100.13 \mathrm{MHz}$ & Quantification & {$[20]$} \\
\hline $\begin{array}{l}\text { Saturates, cis- and trans-monounsaturates, poly- } \\
\text { unsaturates in fats and oils }\end{array}$ & ${ }^{13} \mathrm{C}, 125 \mathrm{MHz}$ & Nutritional & {$[21]$} \\
\hline Fatty acids in olive oil & ${ }^{1} \mathrm{H}, 500 \mathrm{MHz}$ & Origin characterization, cultivar & {$[22]$} \\
\hline Fatty acids in olive oil & ${ }^{1} \mathrm{H}, 500 \mathrm{MHz}$ & Geographic characterization & [5] \\
\hline Fatty acids and squalene in olive oil & ${ }^{1} \mathrm{H}, 100.13 \mathrm{MHz}$ & $\begin{array}{l}\text { Chemical composition, classification and metabo- } \\
\text { lomic profile }\end{array}$ & [23] \\
\hline Unsaponifiable fraction of virgin olive & ${ }^{1} \mathrm{H}, 500 \mathrm{MHz}$ & $\begin{array}{l}\text { Authentication, Geographic characterization, } \\
\text { Fingerprinting }\end{array}$ & {$[24]$} \\
\hline $\begin{array}{l}\text { Triacylglycerols and same minor compounds in } \\
\text { olive oil }\end{array}$ & ${ }^{1} \mathrm{H}, 500 \mathrm{MHz}$ & Fingerprinting, stability & {$[25]$} \\
\hline Minor extra virgin olive oil components & ${ }^{1} \mathrm{H}, 400 \mathrm{MHz}$ & Characterization & {$[26]$} \\
\hline Fatty acids & ${ }^{1} \mathrm{H}, 600 \mathrm{MHz}$ & Discrimination of olive oil from edible oils & {$[27]$} \\
\hline
\end{tabular}

and $-\mathrm{CH}_{3}$ in a phase opposite to $\mathrm{CH}_{2} ; 90^{\circ}$ angle gives only $-\mathrm{CH}$ groups, the others being suppressed; $45^{\circ}$ angle gives all carbons with attached protons (regardless of number) in phase. Indeed, the polarization transfer from ${ }^{1} \mathrm{H}$ to ${ }^{13} \mathrm{C}$ has the secondary advantage of increasing the sensitivity over the normal ${ }^{13} \mathrm{C}$ spectrum, which has a modest enhancement from the nuclear overhauser effect (NOE) due to the ${ }^{1} \mathrm{H}$ decoupling.

In this article, we will discuss the attributes of $1 \mathrm{D}$ multinuclear NMR spectroscopy as an important tool for profiling the chemical composition of olive oil samples, mainly focused on fatty acids composition and triacylglycerol fraction. To achieve this purpose, a Portuguese Olive Oil (Cobrançosa cv.) has been selected as a case study. To pursue this study, ${ }^{1} \mathrm{H}$ NMR, ${ }^{13} \mathrm{C}$ NMR, ${ }^{13} \mathrm{C}$ NMR DEPT135, ${ }^{13} \mathrm{C}$ NMR DEPT90 and ${ }^{13} \mathrm{C}$ NMR DEPT45 techniques have been applied. In particular, the DEPT experiments will be used to assess how the use of different angle values in only one pulse sequence influences the interpretation of ${ }^{13} \mathrm{C}$ NMR spectra and its usefulness for the characterization of olive oil samples based on the fatty acid composition and triacylglycerol fraction. To the best of our knowledge, there have been no reports on the use of ${ }^{13} \mathrm{C}$ NMR DEPT90 spectroscopy or of ${ }^{13} \mathrm{C}$ NMR DEPT135 spectroscopy for classifying olive oils.

\section{Materials and methods}

\section{Olive oil sample}

A $500 \mathrm{~mL}$ of monovarietal Portuguese extra virgin olive oil from Cobrançosa cv. was obtained in commercial milling facilities at INIAV-Elvas (Portugal), from fresh olives collected at that place over the period October and November 2016 .

\section{Sample preparation}

For the sample preparation, $100 \mu \mathrm{L}$ of the olive oil under analysis and $10 \mu \mathrm{L}(0.072 \mathrm{mmol}, 8.64 \mathrm{mg})$ of mesitylene (internal standard-IS) were dissolved in $500 \mu \mathrm{L}$ of deuterated chloroform and were placed in a $5 \mathrm{~mm}$ diameter NMR tube. Deuterated chloroform $99.8 \%$ was obtained from Cambridge Isotope Laboratories, Inc. and used as a solvent. Mesitylene 98\% was purchased from SigmaAldrich and used as an internal standard for normalizing the carbon resonances in the ${ }^{13} \mathrm{C}$ spectra. All compounds were used as received without any purification. All analysis was performed in quadruplicate. 


\section{Instrumentation}

The 1D multinuclear NMR spectroscopy $\left({ }^{1} \mathrm{H}\right.$ NMR, ${ }^{13} \mathrm{C}$ NMR) and the ${ }^{13} \mathrm{C}$ NMR DEPT experiments [1] $\left({ }^{13} \mathrm{C}\right.$ NMR DEPT $45,{ }^{13} \mathrm{C}$ NMR DEPT90 and ${ }^{13} \mathrm{C}$ NMR DEPT135) were conducted on a Bruker Advance III $400 \mathrm{MHz}$ spectrometer (Madrid- Spain) equipped with a wide band (BBO) observation probe at a temperature of $303 \mathrm{~K}$.

\section{NMR methodologies}

Each sample was subjected to five 1D-NMR experiments that included ${ }^{1} \mathrm{H}$ NMR, ${ }^{13} \mathrm{C}$ NMR, ${ }^{13} \mathrm{C}$ NMR DEPT90, ${ }^{13} \mathrm{C}$ NMR DEPT $45,{ }^{13} \mathrm{C}$ NMR DEPT135. These pulse sequences were installed in the Bruker TOPSPIN $3.2 \mathrm{pl} 6$ suit and the analysis of the samples was facilitated by the application of the ICON-NMR user interface installed with the same software suit. The free induction decay (FID) acquisition parameters for this standard single pulse test were as follows:

1. (zg30) in ${ }^{1} \mathrm{H}$ NMR spectral width $(\mathrm{SW})=20.64 \mathrm{ppm}$, dummy scans $(\mathrm{DS})=2$, number of scans $(\mathrm{NS})=16$, the acquisition time $(\mathrm{AQ})=4.089 \mathrm{~s}$, and the received gain $(R G)=10$, giving a total run time of $1 \mathrm{~min}$ and $32 \mathrm{~s}$;

2. (zgpg30) at ${ }^{13} \mathrm{C}$ NMR: spectral width $(\mathrm{SW})=238.89 \mathrm{ppm}$, dummy scans $(\mathrm{DS})=4$, the number scans $(\mathrm{NS})=1024$, acquisition time $(\mathrm{AQ})=1.3631 \mathrm{~s}$, and the receiver gain $(R G)=2050$, giving a total running time of $58 \mathrm{~min}$ and $42 \mathrm{~s}$.

3. (deptsp45) at ${ }^{13} \mathrm{C}$ NMR DEPT45 and for the standard single pulse test (deptsp90) at ${ }^{13} \mathrm{C}$ NMR DEPT90: spectral width $(\mathrm{SW})=238.89 \mathrm{ppm}$, dummy scans $(\mathrm{DS})=4$, the number of scans $(\mathrm{NS})=256$, the acquisition time $(\mathrm{AQ})=1.3631 \mathrm{~s}$, and the receiver gain $(\mathrm{RG})=2050$, with a total run time of $14 \mathrm{~min}$ and $46 \mathrm{~s}$ for each of the pulse sequences.

4. (deptsp135) at ${ }^{13} \mathrm{C}$ NMR DEPT135: spectral width $(\mathrm{SW})=160.29 \mathrm{ppm}$, dummy scans $(\mathrm{DS})=4$, number of scans $(\mathrm{NS})=256$, acquisition time $(\mathrm{AQ})=2.0316 \mathrm{~s}$, and receiver gain $(R G)=2050$, giving a total run time of $14 \mathrm{~min}$ and $46 \mathrm{~s}$.

The shaped pulse used in our DEPT experiments is defined by the Topspin parameter SPNAM5 $=$ Crp60comp 4 . It is an adiabatic pulse with a composite smoothed CHIRP shape with the following characteristics: sweep width: $60 \mathrm{kHz}$, duration: $2 \mathrm{~ms}$, radiofrequency field intensity (i.e., gB1/2p): $9772 \mathrm{~Hz}$.

The generated files were handled by Topspin software $3.2 \mathrm{pl} 6$.

In the ${ }^{13} \mathrm{C}$ NMR spectra, mesitylene resonances appeared at $\delta 137.68 \mathrm{ppm}(\mathrm{C}-1,3,5), \delta 126.91 \mathrm{ppm}(\mathrm{C}-2,4,6)$ and $\delta$ $21.20 \mathrm{ppm}\left(\mathrm{CH}_{3}\right)$.

\section{Results and discussion}

The ${ }^{1} \mathrm{H}$ NMR analysis of a monovarietal olive oil from Cobrançosa cv. has been performed and Fig. 2 depicts the ${ }^{1} \mathrm{H}$ NMR spectrum obtained in this study. In fact, ${ }^{1} \mathrm{H}$ NMR constitutes the first tool that is applied in NMR-based assays due to the higher sensitivity and lower relaxation times of the proton nuclei relative to the less sensitive ${ }^{13} \mathrm{C}$ NMR nuclei. However, the presence of scalar coupling between neighboring protons and the much smaller chemical shift ranges for protons ( $15 \mathrm{ppm}$, generally $0-10 \mathrm{ppm})$ often results in spectra with overlapping signals, which makes spectral analysis much more complicated [2]. Table 2 shows the respective chemical shifts and proton assignments. In some
Fig. $2{ }^{1} \mathrm{H}$ NMR spectrum $\left(400 \mathrm{MHz}\right.$ in $\mathrm{CDCl}_{3}$ ) of the monovarietal Portuguese olive oil Cobrançosa cv

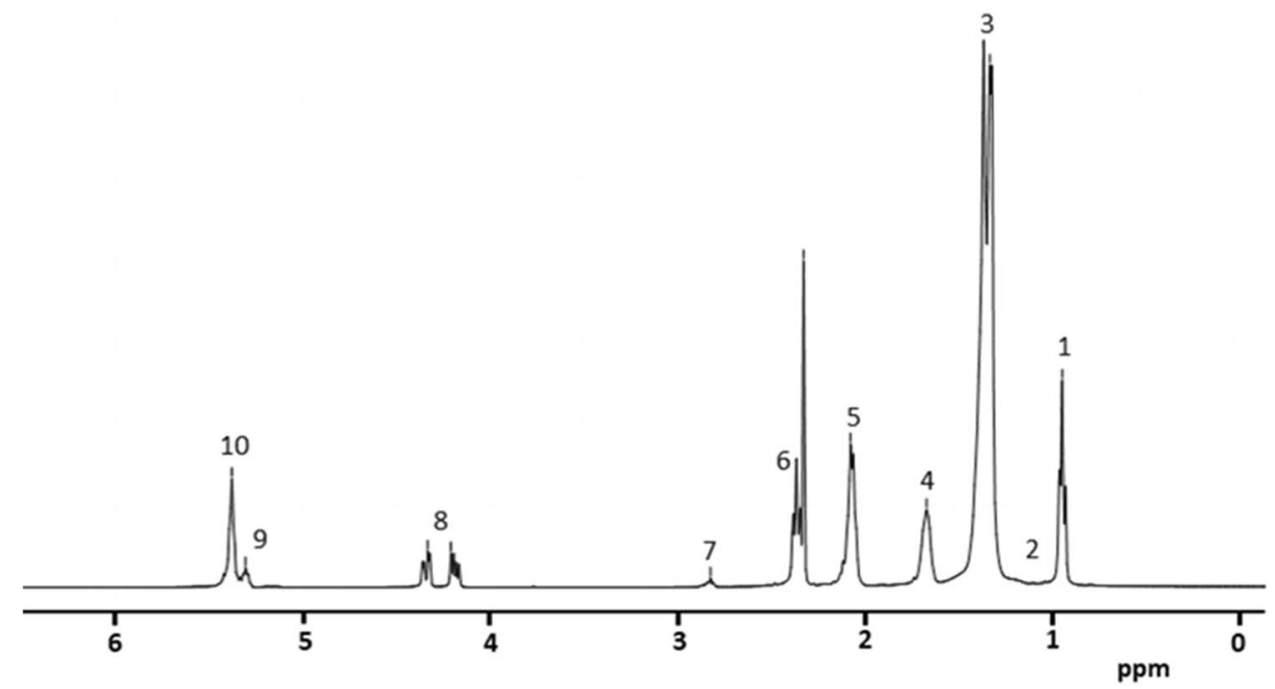


Table 2 Chemical shifts and proton assignments of a 1H NMR spectrum of the monovarietal Portuguese olive oil Cobrançosa cv

\begin{tabular}{lll}
\hline Signal & $\begin{array}{l}\text { Chemical } \\
\text { shifts (ppm) }\end{array}$ & Functional groups \\
\hline 1 & $0.83-0.93$ & $-\mathrm{CH}_{3}$ All acids except linolenyl group \\
2 & $0.93-1.03$ & $-\mathrm{CH}_{3}$ Linolenyl group \\
3 & $1.22-1.42$ & $-\left(\mathrm{CH}_{2}\right)_{\mathrm{n}}$ All acyl chains \\
4 & $1.52-1.70$ & $-\mathrm{OCO}^{-} \mathrm{CH}_{2}-\mathrm{CH}_{2}-$ All acyl chains \\
5 & $1.94-2.14$ & $-\mathrm{CH}_{2}-\mathrm{CH}=\mathrm{CH}-$ All unsaturated fatty acids \\
6 & $2.23-2.36$ & $-\mathrm{OCO}-\mathrm{CH}_{2}-\mathrm{All}$ acyl chains \\
7 & $2.70-2.84$ & $=\mathrm{CH}-\mathrm{CH} \mathbf{H}_{2}-\mathrm{CH}=$ Linoleyl and linolenyl \\
8 & $4.10-4.32$ & $-\mathrm{CH} \mathrm{OCOR}_{2} \mathrm{Olycerol}$ (triacylglycerols) \\
9 & $5.20-5.26$ & $>\mathrm{CHOCOR}$ Glycerol (triacylglycerols) \\
10 & $5.26-5.40$ & $-\mathrm{CH}=\mathrm{CH}-$ All unsaturated fatty acids \\
\hline
\end{tabular}

spectra, the signal around $\delta 0.95$ ppm was not observed, probably due to the low quantity of the component that gives rise to this signal, making it difficult to be detected in the spectrum.

As seen in Fig. 2 and listed in Table 2, ${ }^{1} \mathrm{H}$ NMR spectrum of the olive oil under study shows nine resonance signals that are attributed to the fatty acyl chain and the glyceryl protons of the TAG component. Because the different fatty acids are similar, in free form or as glyceride esters, most of the ${ }^{1} \mathrm{H}$ NMR signals overlap, making it very difficult to discriminate between these components [31]. The olefinic proton $-\mathrm{CH}=\mathrm{CH}-$ of unsaturated fatty acids appears around $\delta 5.38 \mathrm{ppm}$ in the form of a multiplet $(\mathrm{m})$, at $\delta 5.31 \mathrm{ppm}$ is the backbone of glycerol moiety and appears also in the form of a multiplet $(\mathrm{m})$. The signals of the glycerol protons $-\mathrm{CH}_{2} \mathrm{OCOR}$ found between $\delta 4.20-4.33 \mathrm{ppm}$ appear in the form of a double doublet (dd). The linoleyl and linolenyl protons $\left(=\mathrm{CH}-\mathrm{CH}_{2}-\mathrm{CH}=\right)$ appear at $\delta 2.81 \mathrm{ppm}$, and all the acyl chain protons appear at $\delta 2.31,1.65$ and $1.31 \mathrm{ppm}$, respectively. The unsaturated fatty acids protons $\left(-\mathrm{CH}_{2}-\mathrm{CH}=\mathrm{CH}-\right)$ appear at $\delta 2.06 \mathrm{ppm}$, and the most upfield signal at $\delta 0.92 \mathrm{ppm}$ which is observed for all the fatty acids (except linolenyl) appears as a triplet (t). All the signals observed and their multiplicities are similar to those described in the literature for this food sample matrix [2, 6].

${ }^{13} \mathrm{C}$ NMR spectrum was also obtained for the same monovarietal olive oil. The main resonances observed belong to triacylglycerides (Fig. 1) and the spectrum can be divided into four principal regions in accordance with the different carbon groups [29, 32]. The first resonances appearing in the spectrum in the region $\delta 172-174$ ppm belong to the carbonyl carbons of the fatty acids, the second resonances appearing to the next region in the spectrum at $\delta$ 124-134 ppm belong to the olefinic carbons of the unsaturated fatty acids, the resonances appearing in the third region, $\delta 60-72 \mathrm{ppm}$, belong to the carbons of the glycerol structure, and the resonances appearing in the fourth region of the spectrum, $\delta 10-35 \mathrm{ppm}$, belong to the aliphatic carbons [2, 28, 32, 33]. Figure 3 depicts the ${ }^{13} \mathrm{C}$ NMR spectrum of the monovarietal olive oil under study, with the assignment of the different resonances. ${ }^{13} \mathrm{C}$ NMR spectra are obtained with high signal-to-noise ratio in relation to the low natural abundance of the carbon-13 nuclei and the low sensitivity is due to a small gyromagnetic ratio $[17,28]$.

Compared to the previous ${ }^{1} \mathrm{H}$ NMR spectrum shown (Fig. 2), the ${ }^{13} \mathrm{C}$ NMR spectrum (Fig. 3) is more complex but furnishing more information on the composition of the olive oil sample. As previously described, the resonances appearing in the spectrum are in agreement with the reported in the literature. By analyzing the ${ }^{13} \mathrm{C}$ NMR spectrum (Fig. 3), it was possible to observe 41 resonance signals, mostly due to the triacylglycerol (TAG) fraction [2]. As expected, those resonances arise in four principal regions-namely
Fig. $3{ }^{13} \mathrm{C}$ NMR spectrum $\left(100.13 \mathrm{MHz}\right.$ in $\left.\mathrm{CDCl}_{3}\right)$ of the monovarietal Portuguese Olive Oil Cobrançosa cv [IS-internal standard, $\mathrm{S}$ - solvent $\left.\left(\mathrm{CDCl}_{3}\right)\right]$

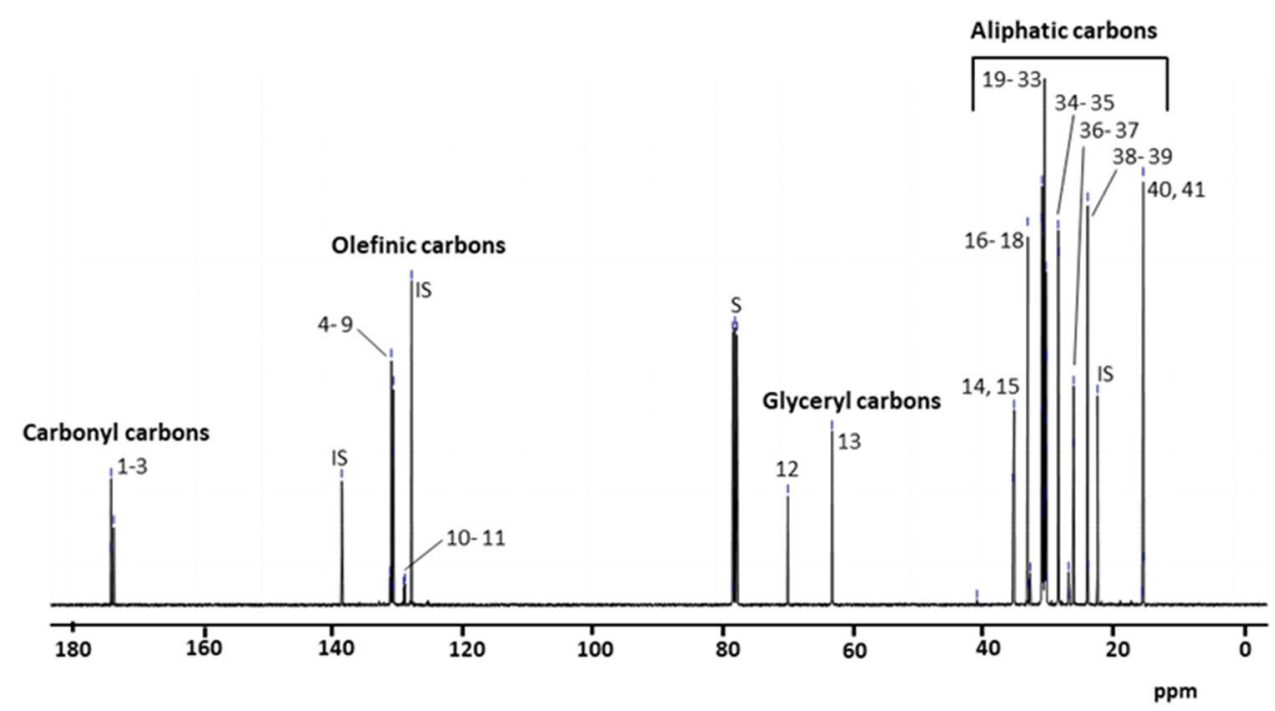


the carbonyl carbons of the fatty acids, the olefinic carbons, the glycerol carbons and the aliphatic carbons (as labeled in Fig. 3). Table 3 lists the respective chemical shifts and the corresponding carbon signals for the ${ }^{13} \mathrm{C}$ NMR spectrum of the olive oil under study.
Lastly, to elucidate the usefulness of ${ }^{13} \mathrm{C}$ NMR DEPT tool on the analysis of the triacylglycerol fraction of olive oil samples owing to the simplification on the peak assignments of ${ }^{13} \mathrm{C}$ NMR spectra, several ${ }^{13} \mathrm{C}$ NMR experiments using different angle values $\left(45^{\circ}, 90^{\circ}\right.$ and $\left.135^{\circ}\right)$ in only one pulse
Table 3 Complete 1D NMR analysis of a typical Portuguese olive oil sample of Cobrançosa $\mathrm{cv}$

\begin{tabular}{|c|c|c|c|c|c|}
\hline \multirow[t]{2}{*}{ Signal } & \multicolumn{4}{|c|}{ Chemical shifts (ppm) } & \multirow[t]{2}{*}{ Functional group $^{\mathrm{a}}$} \\
\hline & ${ }^{13} \mathrm{C}$ NMR & ${ }^{13} \mathrm{C}$ DEPT45 & ${ }^{13} \mathrm{C}$ DEPT90 & ${ }^{13} \mathrm{C}$ DEPT 135 & \\
\hline 1 & 173.26 & - & - & - & Carbonyl carbon $\mathrm{S}$ \\
\hline 2 & 173.23 & - & - & - & Carbonyl carbon $\mathrm{O}$ \\
\hline 3 & 172.83 & - & - & - & Carbonyl carbon $\mathrm{O}$ \\
\hline 4 & 130.21 & 130.20 & 130.22 & 130.20 & $\mathrm{~L} 13 \alpha \beta$ \\
\hline 5 & 130.01 & 130.01 & 130.02 & 130.01 & $\mathrm{O} 10 \alpha \beta$ \\
\hline 6 & 129.93 & 129.93 & 129.94 & 129.93 & $\mathrm{~L} 9 \alpha$ \\
\hline 7 & 129.83 & 129.83 & 129.84 & 129.83 & L9 $\beta$ \\
\hline 8 & 129.71 & 129.71 & 129.72 & 129.71 & O9 $\alpha$ \\
\hline 9 & 129.69 & 129.69 & 129.70 & 129.69 & O9 $\beta$ \\
\hline 10 & 128.10 & 128.10 & 128.10 & 128.10 & $\mathrm{~L} 10 \alpha \beta$ \\
\hline 11 & 127.91 & 127.92 & 127.91 & 127.91 & $\mathrm{~L} 12 \alpha \beta$ \\
\hline 12 & 68.91 & 68.91 & 68.89 & 68.90 & Gl $\beta$ \\
\hline 13 & 62.11 & 62.10 & - & 62.11 & Gl $\alpha$ \\
\hline 14 & 34.20 & 34.20 & - & 34.20 & $\mathrm{O}, \mathrm{L} 2 \beta$ \\
\hline 15 & 34.04 & 34.04 & - & 34.04 & $\mathrm{~S} 2 \alpha$ \\
\hline 16 & 31.95 & 31.95 & - & 31.95 & $\mathrm{~S} 16 \alpha / \mathrm{O} 16 \alpha \beta$ \\
\hline 17 & 31.83 & 31.82 & - & 31.83 & uk \\
\hline 18 & 31.56 & 31.56 & - & 31.56 & $\mathrm{~L} 16 \alpha \beta$ \\
\hline 19 & 29.80 & 29.80 & - & 29.80 & $\mathrm{O} 12 \alpha \beta$ \\
\hline 20 & 29.74 & 29.74 & - & 29.74 & uk \\
\hline 21 & 29.71 & 29.70 & - & 29.71 & uk \\
\hline 22 & 29.67 & 29.66 & - & 29.67 & uk \\
\hline 23 & 29.57 & 29.57 & - & 29.57 & $\mathrm{O} 14 \alpha \beta$ \\
\hline 24 & 29.52 & 29.52 & - & 29.52 & $\mathrm{~S} 6 \alpha$ \\
\hline 25 & 29.41 & 29.41 & - & 29.41 & $\mathrm{~S} 15 \alpha$ \\
\hline 26 & 29.36 & 29.36 & - & 29.37 & $\mathrm{O} 15,13 \alpha \beta$ \\
\hline 27 & 29.31 & 29.31 & - & 29.32 & $\mathrm{~S} 5 \alpha$ \\
\hline 28 & 29.23 & 29.23 & - & 29.24 & $\mathrm{O}, \mathrm{L} 5 \beta$ \\
\hline 29 & 29.21 & 29.21 & - & 29.22 & $\mathrm{O}, \mathrm{L} 5 \alpha$ \\
\hline 30 & 29.15 & 29.14 & - & 29.15 & $\mathrm{~S} 4 \alpha-\mathrm{O}, \mathrm{L} 6 \alpha, \beta-\mathrm{O}, \mathrm{L} 4 \alpha \mathrm{uk}$ \\
\hline 31 & 29.12 & 29.12 & - & 29.12 & $\mathrm{~S} 4 \alpha-\mathrm{O}, \mathrm{L} 6 \alpha, \beta-\mathrm{O}, \mathrm{L} 4 \alpha$ \\
\hline 32 & 29.08 & 29.08 & - & 29.08 & $\mathrm{O}, \mathrm{L} 4 \beta$ \\
\hline 33 & 29.03 & 29.02 & - & 29.03 & uk \\
\hline 34 & 27.25 & 27.25 & - & 27,25 & $\mathrm{O} 11 \alpha \beta$ \\
\hline 35 & 27.20 & 27.20 & - & 27.20 & $\mathrm{~L} 8 \alpha \beta, \mathrm{O} 8 \alpha \beta$ \\
\hline 36 & 25.65 & 25.65 & - & 25.65 & $\mathrm{~L} 11 \alpha \beta$ \\
\hline 37 & 24.87 & 24.87 & - & 24.87 & $\mathrm{O}, \mathrm{L} 3 \alpha \beta, \mathrm{S} 3 \alpha$ \\
\hline 38 & 22.72 & 22.72 & - & 22.73 & $\mathrm{~S} 17 \alpha, \mathrm{O} 17 \alpha \beta$ \\
\hline 39 & 22.61 & 22.61 & - & 22.62 & $\mathrm{~L} 17 \alpha \beta$ \\
\hline 40 & 14.14 & 14.13 & - & 14.14 & $\mathrm{~S} 18 \alpha, \mathrm{O} 18 \alpha \beta$ \\
\hline 41 & 14.10 & 14.09 & - & 14.10 & $\mathrm{~L} 18 \alpha \beta$ \\
\hline
\end{tabular}

${ }^{a}$ Carbon atoms of the acyl chain, saturated (S) oleic acid, (L) linoleic acid, (uk) unknown signal, (Gl) glycerol, and positions 1 (3) and 2-glycerol are indicated by the Greek letters $\alpha$ and $\beta$, respectively 
sequence were applied to the monovarietal Portuguese olive oil of Cobrançosa cv. The spectra of ${ }^{13} \mathrm{C}$ NMR DEPT45, ${ }^{13} \mathrm{C}$ NMR DEPT90 and ${ }^{13} \mathrm{C}$ NMR DEPT135 experiments are depicted in Figs. 4, 5 and 6.
As shown in Fig. 4, the ${ }^{13} \mathrm{C}$ NMR DEPT45 spectrum presents 38 characteristic resonances. Table 3 lists the respective chemical shifts and the corresponding assignment of the carbon signals. It should be noted that this
Fig. $4{ }^{13} \mathrm{C}$ NMR DEPT45 spectrum $\left(100.13 \mathrm{MHz}\right.$ in $\mathrm{CDCl}_{3}$ ) of the monovarietal Portuguese Olive Oil Cobrançosa cv (ISinternal standard)

Fig. $5{ }^{13} \mathrm{C}$ NMR DEPT90 spectrum $\left(100.13 \mathrm{MHz}\right.$ in $\mathrm{CDCl}_{3}$ ) of the monovarietal Portuguese olive oil sample Cobrançosa cv (IS-internal standard)

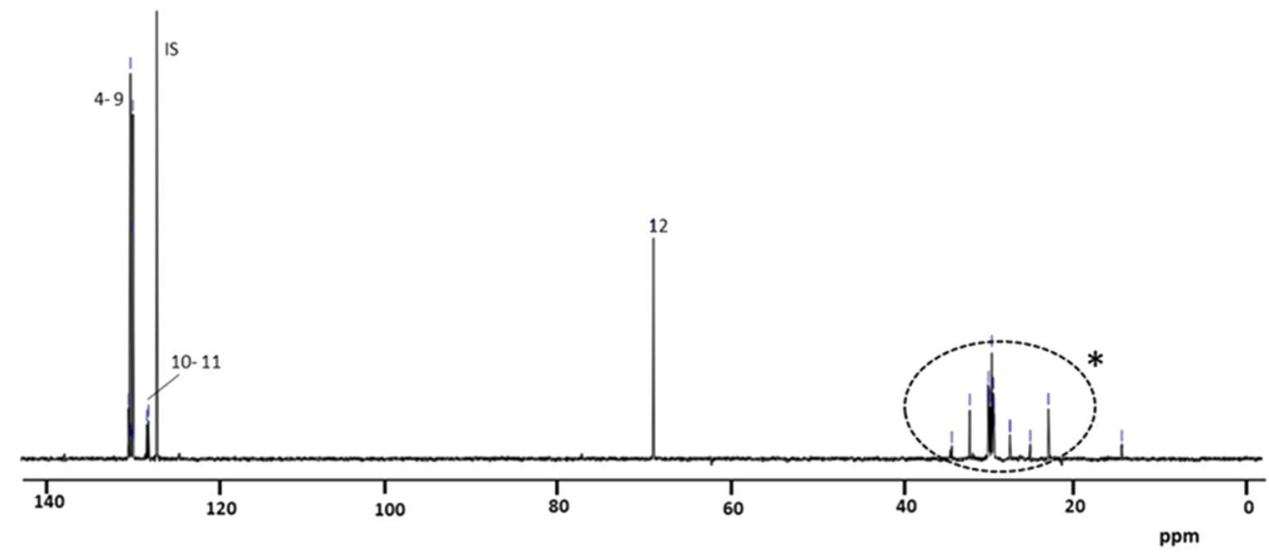

Fig. $6{ }^{13} \mathrm{C}$ NMR DEPT135 spectrum $(100.13 \mathrm{MHz}$ in $\mathrm{CDCl}_{3}$ ) of the monovarietal Portuguese olive oil Cobrançosa $\mathrm{cv}$

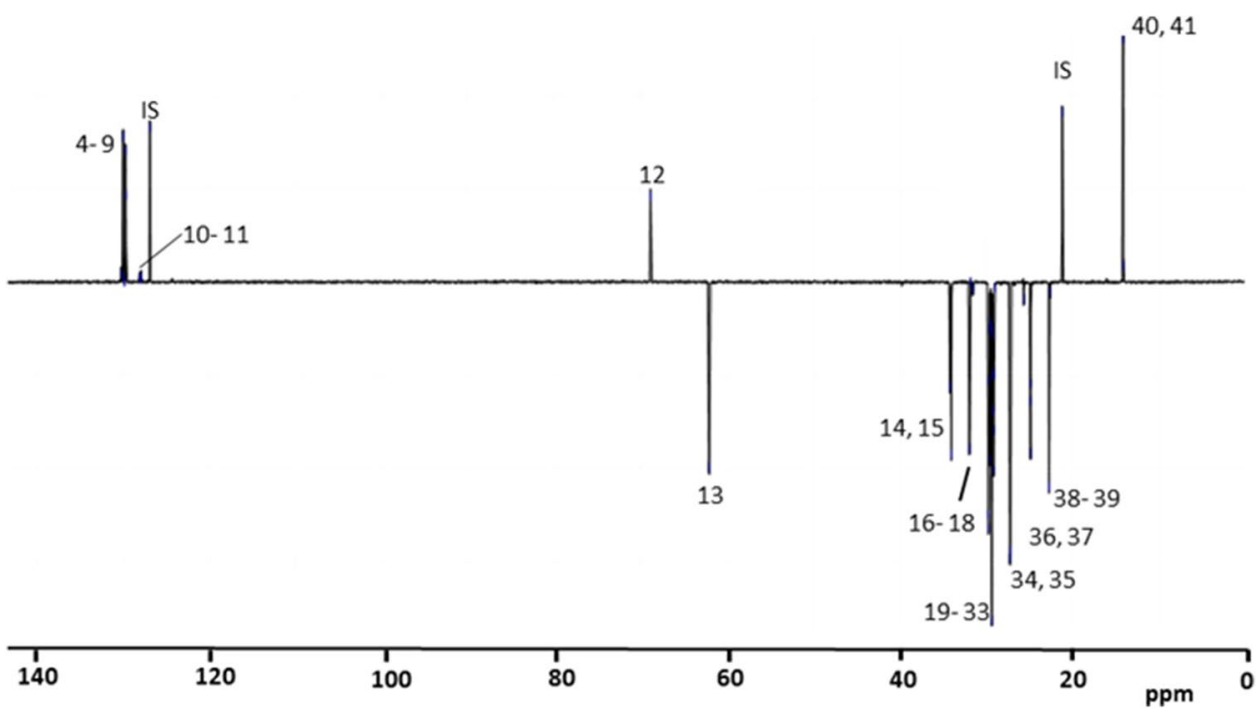


carbon-13 editing technique so far has only been used in one particular case for the analysis of olive oils [1].

It is well known that ${ }^{13} \mathrm{C}$ NMR DEPT45 tool produces spectra with positive signals for the $\mathrm{CH}, \mathrm{CH}_{2}$ and $\mathrm{CH}_{3}$ (all protonated carbons), with the signals of the quaternary carbons including the signals of the deuterated chloroform solvent not detected or observed.

The ${ }^{13} \mathrm{C}$ NMR DEPT90 spectrum for the same olive oil sample was also obtained (Fig. 5) and the corresponding assignment of the chemical shifts is indicated in Table 3.

${ }^{13} \mathrm{C}$ NMR DEPT90 tool produces spectra with only $\mathrm{CH}$ signals; therefore, only carbon signals with single attached hydrogen were observed. However, this spectrum displays weak signals between $\delta 35$ and $20 \mathrm{ppm}$. In fact, it is not uncommon to observe weak $\mathrm{CH}_{2}$ and $\mathrm{CH}_{3}$ resonances in the ${ }^{13} \mathrm{C}$ NMR DEPT 90 spectrum of some samples [17], due to the requirement for a perfect $90^{\circ}$ pulse alignment for complete $\mathrm{CH}_{2}$ and $\mathrm{CH}_{3}$ editing, but these are generally significantly attenuated as we see above (region labeled in the spectrum with $*$ ).

The ${ }^{13} \mathrm{C}$ NMR DEPT135 spectrum for the same olive oil sample was also obtained (Fig. 6) and the corresponding assignment of the peaks is listed in Table 3.

${ }^{13} \mathrm{C}$ NMR DEPT135 spectrum presents the resonances assigned to $\mathrm{CH}$ and $\mathrm{CH}_{3}$ units as positive signals contrary to the $\mathrm{CH}_{2}$ resonances which are negative. In this pulse sequence, all carbons having bound protons are observed. This could be very useful for discriminating the different types of carbons.

In overall, the spectra represented in the Figs. 4, 5, 6 and the assigned chemicals shifts are coincident to that given in the literature [2, 29, 32] (Table 3). Particularly, both the ${ }^{13} \mathrm{C}$ NMR DEPT135 (Fig. 6) and the ${ }^{13} \mathrm{C}$ NMR DEPT45 (Fig. 5) give more specific information. Naturally, there is the absence of the fatty acid carbonyl groups, and other quaternary carbon resonances. Indeed, quaternary carbon signals are absent from all polarization transfer spectra that are set up to exploit large single-bond J-coupling [17]. The resonance signals are attributed to the TAG units that appear between $\delta 10 \mathrm{ppm}$ and $\delta 135 \mathrm{ppm}$. The ${ }^{13} \mathrm{C}$ NMR DEPT135 and the ${ }^{13} \mathrm{C}$ NMR DEPT45 spectra have the strong advantage that compared with the broadband ${ }^{13} \mathrm{C}$ NMR spectrum they afford significant structural and compositional information, more rapidly than with broadband ${ }^{13} \mathrm{C}$ NMR and with better sensitivity due to the polarization transfer [17]. By comparison, the ${ }^{13} \mathrm{C} N M R$ DEPT90 spectrum shows only nine resonances attributed to the olefinic and glycerol carbons owing to the more limited polarization transfer method, which restricts the identification into only the primary carbons.

${ }^{13} \mathrm{C}$ NMR DEPT90 is more limited polarization transfer method, as it is limited to identification of only the primary carbons, and as such presents limited sample points for the key multivariate statistical methods that are necessary to validate the geographical origin of the olive oil.

\section{Conclusions}

In summary, this study has involved the application of several 1D NMR techniques-namely ${ }^{1} \mathrm{H}$ NMR, ${ }^{13} \mathrm{C}$ NMR, ${ }^{13} \mathrm{C}$ NMR DEPT45, ${ }^{13} \mathrm{C}$ NMR DEPT90 and ${ }^{13} \mathrm{C}$ NMR DEPT135, in the analysis of the fatty acid composition and TAG fractions of a typical monovarietal Portuguese Olive Oil sample (Cobrançosa cv.), aiming to obtain insights about the usefulness of the combined NMR techniques and, particularly, the ${ }^{13} \mathrm{C}$ NMR DEPT tools on the straightforward assessment of the geographical origin of olive oil samples.

Generally, in the NMR-based study developed in this work, all the obtained data coincided satisfactorily with the data found in the literature. It should be noted that ${ }^{13} \mathrm{C} N \mathrm{NMR}$ analysis provided more useful information than that obtained from ${ }^{1} \mathrm{H}$ NMR technique. Thus, ${ }^{13} \mathrm{C}$ NMR technique seems to be a powerful tool to be used on olive oil authentication and traceability.

Particularly for the ${ }^{13} \mathrm{C}$ NMR DEPT tool, the ${ }^{13} \mathrm{C}$ NMR DEPT45 experiment was shown to be a suitable approach, particularly in the context of its application in multivariate statistical analysis. Moreover, as far as we are aware, there has only been one report in the literature to date [1] on its application in this context for the analysis of Italian olive oils. Although ${ }^{13} \mathrm{C}$ NMR DEPT90 and ${ }^{13} \mathrm{C}$ NMR DEPT135 have never been explored for olive oil sample analysis, ${ }^{13} \mathrm{C}$ NMR DEPT135 seems to be a promising tool for the characterization of the TAG fraction of olive oil samples. As discussed above, ${ }^{13} \mathrm{C}$ NMR DEPT45 and ${ }^{13} \mathrm{C}$ NMR DEPT135 have several advantages, compared with ${ }^{13} \mathrm{C}$ broadband NMR, including (1) greater sensitivity compared to broadband ${ }^{13} \mathrm{C}$ NMR and (2) shorter analytical time, which are highly desirable from the stand point of multi-sample analysis for multivariate statistical treatment in the determination of the geographical origin of the olive oil. As expected, the suitability of ${ }^{13} \mathrm{C}$ NMR DEPT 90 data for the purpose of this work is very limited since only $-\mathrm{CH}$ groups are detected, hampering the use of this tool for multivariate statistical analysis. Nonetheless, it can be used as a complimentary method to support structural and compositional analysis of the olive oil samples. Thus, ${ }^{13} \mathrm{C}$ NMR DEPT45 and ${ }^{13} \mathrm{C}$ NMR DEPT135 are complementary tools contributing to an accurate ascertain of the fatty acid composition and TAG fraction of the olive oil under study.

In overall, compared to other analytical methods abovementioned (namely chromatographic ones), these 1D-NMR methods allow for an effective quality assessment of olive oils, which can be undertaken in a fraction of the time required using the other standard techniques, as well as 
limited sample preparation issues. Moreover, with the inexorable advancements taking place in the development of more sensitive 1D NMR techniques, the use of this approach for olive oil analysis-particularly from the stand-point of origin and authenticity - is expected to become an even more prominent and standard technique in the near future.

Acknowledgements The authors thank Project "Por3O-Portuguese Olive Oil Omics for traceability and authenticity-PTDC/AGRPRO/2003/2014, funding by European Regional Development Fund (FEDER) and National Funds through Fundação para a Ciência e a Tecnologia (FCT); Project "MedOOmics-Mediterranean Extra Virgin Olive Oil Omics: profiling and fingerprinting- Arimnet2/0001/2015" funding by the National Funds through Fundação para a Ciência e a Tecnologia (FCT); and FEDER funds through the Operational Program for Competitive Factors (COMPETE) for funding the FCT Projects UID/AGR/00115/2019 and UID/QUI/0619/2016, respectively. Nuno Martins acknowledges French National Agency for Research (ANR15-ARM2-0002-04) supported by the European Union's Seventh Framework Programme for research, technological development and demonstration under Grant Agreement Number 618127 (ARIMNet2).

\section{Compliance with ethical standards}

Conflict of interest The authors declare that they have no conflict of interest.

Compliance with ethics requirements This article does not contain any studies with human or animal subjects.

\section{References}

1. Vlahov G, Schiavone C, Simone N (2001) Quantitative ${ }^{13}$ C NMR method using the DEPT pulse sequence for the determination of the geographical origin (DOP) of olive oils. Magn Reson Chem 39(11):689-695. https://doi.org/10.1002/mrc.929

2. Dais P, Hatzakis E (2013) Quality assessment and authentication of virgin olive oil by NMR spectroscopy: a critical review. Anal Chim Acta 765:1-27. https://doi.org/10.1016/j.aca.2012.12.003

3. Gunstone F (2011) Vegetable oils in food technology: composition, properties and uses. Wiley, New York

4. Regulation C (1992) Council Regulation (EEC) No. 2081/92 of 14 July 1992 on the protection of geographical indications and designations of origin for agricultural products and foodstuffs. Off. J. Eur. Union 208, pp 1-8

5. Rongai D, Sabatini N, Del Coco L, Perri E, Del Re P, Simone N, Marchegiani D, Fanizzi FP (2017) ${ }^{1} \mathrm{H}$ NMR and multivariate analysis for geographic characterization of commercial extra virgin olive oil: a possible correlation with climate data. Foods 6(11):96-105. https://doi.org/10.3390/foods6110096

6. Knothe G, Kenar JA (2004) Determination of the fatty acid profile by ${ }^{1} \mathrm{H}-\mathrm{NMR}$ spectroscopy. Eur J Lipid Sci Technol 106(2):88-96. https://doi.org/10.1002/ejlt.200300880

7. Miyake Y, Yokomizo K, Matsuzaki N (1998) Determination of unsaturated fatty acid composition by high-resolution nuclear magnetic resonance spectroscopy. J Am Oil Chem Soc 75(12):1091-1094. https://doi.org/10.1007/s11746-998-0118-4

8. Yang Y, Ferro MD, Cavaco I, Liang Y (2013) Detection and identification of extra virgin olive oil adulteration by GC-MS combined with chemometrics. J Agric Food Chem 61(15):3693-3702. https://doi.org/10.1021/jf4000538
9. Ur Rahman I, Qureshi MN, Ahmad S (2012) Comparative study of fatty acid components in oils of different olive varieties grown in different regions of pakistan by gas chromatographymass spectrometry. J Chin Chem Soc 59(1):46-50. https://doi. org/10.1002/jccs.201000397

10. Mannina L, Sobolev AP (2011) High resolution NMR characterization of olive oils in terms of quality, authenticity and geographical origin. Magn Reson Chem 49(S1):S3-S11. https ://doi.org/10.1002/mrc.2856

11. Girelli CR, Del Coco L, Fanizzi FP (2017) Tunisian extra virgin olive oil traceability in the EEC market: Tunisian/Italian (Coratina) EVOOs blend as a case study. Sustainability 9(8):1471-1481. https://doi.org/10.3390/su9081471

12. Malz F, Jancke H (2005) Validation of quantitative NMR. J Pharm Biomed Anal 38(5):813-823. https://doi.org/10.1016/j. jpba.2005.01.043

13. Sun S, Jin M, Zhou X, Ni J, Jin X, Liu H, Wang Y (2017) The application of quantitative ${ }^{1} \mathrm{H}-\mathrm{NMR}$ for the determination of Orlistat in tablets. Molecules 22(9):1517-1526. https://doi. org/10.3390/molecules22091517

14. Dugo G, Rotondo A, Mallamace D, Cicero N, Salvo A, Rotondo E, Corsaro C (2015) Enhanced detection of aldehydes in extravirgin olive oil by means of band selective NMR spectroscopy. Phys A 420:258-264. https://doi.org/10.1016/j.physa .2014.11.010

15. Vlahov G, Del Re P, Simone N (2003) Determination of geographical origin of olive oils using ${ }^{13} \mathrm{C}$ nuclear magnetic resonance spectroscopy. I-classification of olive oils of the Puglia region with denomination of protected origin. J Agric Food Chem 51(19):5612-5615. https://doi.org/10.1021/jf0207124

16. Vlahov $\mathrm{G}(2005){ }^{13} \mathrm{C}$ nuclear magnetic resonance spectroscopy to check 1, 3-random, 2-random pattern of fatty acid distribution in olive oil triacylglycerols. J Spectrosc 19(2):109-117. https://doi. org/10.1155/2005/765236

17. Sanders JK, Hunter BK (1988) Modern NMR spectroscopy: a guide for chemists, 2nd edn. Oxford University Press, Oxford

18. D'Imperio M, Mannina L, Capitani D, Bidet O, Rossi E, Bucarelli FM, Quaglia GB, Segre A (2007) NMR and statistical study of olive oils from Lazio: a geographical, ecological and agronomic characterization. Food Chem 105(3):1256-1267. https://doi. org/10.1016/j.foodchem.2007.02.045

19. Mannina L, Dugo G, Salvo F, Cicero L, Ansanelli G, Calcagni C, Segre A (2003) Study of the cultivar- composition relationship in Sicilian olive oils by GC, NMR, and statistical methods. J Agric Food Chem 51(1):120-127. https://doi.org/10.1021/jf0256561

20. Nam AM, Bighelli A, Tomi F, Casanova J, Paoli M (2017) Quantification of squalene in olive oil using ${ }^{13} \mathrm{C}$ nuclear magnetic resonance spectroscopy. Magnetochemistry 3(4):34-43. https://doi. org/10.3390/magnetochemistry3040034

21. Gao L, Sedman J, García-González DL, Ehsan S, Sprules T, Van de Voort FR (2009) 13C NMR as a primary method for determining saturates, cis-and trans-monounsaturates and polyunsaturates in fats and oils for nutritional labeling purposes. Eur J Lipid Sci Technol 111(6):612-622. https://doi.org/10.1002/ejlt.200800242

22. Del Coco L, Schena FP, Fanizzi FP (2012) ${ }^{1} \mathrm{H}$ nuclear magnetic resonance study of olive oils commercially available as italian products in the United States of America. Nutrients 4(5):343-355. https://doi.org/10.3390/nu4050343

23. Merchak N, El Bacha E, Khouzam RB, Rizk T, Akoka S, Bejjani J (2017) Geoclimatic, morphological, and temporal effects on Lebanese olive oils composition and classification: a ${ }^{1} \mathrm{H}$ NMR metabolomic study. Food Chem 217:379-388. https://doi.org/10.1016/j. foodchem.2016.08.110

24. Alonso-Salces R, Héberger K, Holland M, Moreno-Rojas J, Mariani C, Bellan G, Reniero F, Guillou C (2010) Multivariate analysis of NMR fingerprint of the unsaponifiable fraction of virgin olive 
oils for authentication purposes. Food Chem 118(4):956-965. https://doi.org/10.1016/j.foodchem.2008.09.061

25. Alonso-Salces RM, Holland MV, Guillou C (2011) ${ }^{1} \mathrm{H}-\mathrm{NMR}$ fingerprinting to evaluate the stability of olive oil. Food Control 22(12):2041-2046. https://doi.org/10.1016/j.foodc ont.2011.05.026

26. Ruiz-Aracama A, Goicoechea E, Guillén MD (2017) Direct study of minor extra-virgin olive oil components without any sample modification. ${ }^{1} \mathrm{H}$ NMR multisupression experiment: a powerful tool. Food Chem 228:301-314. https://doi.org/10.1016/j.foodc hem.2017.02.009

27. Zhang Y, Zhao Y, Shen G, Zhong S, Feng J (2018) NMR spectroscopy in conjugation with multivariate statistical analysis for distinguishing plant origin of edible oils. J Food Compos Anal 69:140-148. https://doi.org/10.1016/j.jfca.2018.03.006

28. Vlahov G (1999) Application of NMR to the study of olive oils. Prog Nucl Magn Reson Spectrose 35(4):341-357

29. Vlahov G, Angelo CS (1996) the structure of triglycerides of monovarietal olive oils: a ${ }^{13} \mathrm{C}-\mathrm{NMR}$ comparative study. Eur J Lipid Sci Technol 98(6):203-205. https://doi.org/10.1002/lipi.1996098060 5
30. Vlahov $\mathrm{G}(2006){ }^{13} \mathrm{C}$ nuclear magnetic resonance spectroscopy to determine olive oil grades. Anal Chim Acta 577(2):281-287. https://doi.org/10.1016/j.aca.2006.06.044

31. Popescu R, Costinel D, Dinca OR, Marinescu A, Stefanescu I, Ionete RE (2015) Discrimination of vegetable oils using NMR spectroscopy and chemometrics. Food Control 48:84-90. https:// doi.org/10.1016/j.foodcont.2014.04.046

32. Sacchi R, Addeo F, Paolillo L (1997) ${ }^{1} \mathrm{H}$ and ${ }^{13} \mathrm{C}$ NMR of virgin olive oil. An overview. Magn Reson Chem 35(13):S133-S145

33. Zamora R, Alba V, Hidalgo FJ (2001) Use of high-resolution ${ }^{13} \mathrm{C}$ nuclear magnetic resonance spectroscopy for the screening of virgin olive oils. J Am Oil Chem Soc 78(1):89-94. https://doi. org/10.1007/s11746-001-0225-Z

Publisher's Note Springer Nature remains neutral with regard to jurisdictional claims in published maps and institutional affiliations. 